\title{
Duas cosmogêneses como chave de leitura para a Ponte Flusseriana do design
}

\section{Sérgio Luciano da Silva}

Doutor; Universidade do Estado de Minas, Belo Horizonte, MG, Brasil sergiolucianosilva@gmail.com

\section{Rita Aparecida da Conceição Ribeiro}

Doutora; Universidade do Estado de Minas, Belo Horizonte, MG, Brasil

rribeiroed@gmail.com

\begin{abstract}
Resumo
O presente artigo procura identificar e compreender matrizes estruturantes do pensamento de Vilém Flusser sobre o design, a partir das narrativas cosmogônicas do Prometeu grego e do livro Gênesis bíblico. Os ensaios de Flusser Sobre a palavra design e $A$ alavanca contra-ataca, por concentrarem sua atenção no tema das origens do conhecimento, justificam sua relação com essas duas cosmogêneses da cultura ocidental e com nossa concepção de uma raiz comum para campos do saber, que na atualidade se encontram problematicamente cindidos e hierarquizados. Para estabelecer interlocução com a filosofia de Flusser, recorremos às posições de Gui Bonsiepe, Rafael Cardoso e Tomás Maldonado. Esses teóricos do design seguem caminhos semelhantes aos do filósofo e questionam a cisão do conhecimento e o papel do design diante das rupturas entre a ciência, a técnica e a arte. Como resultado desse método dialógico e analítico, identificamos e explicitamos capacidades de ampliação da realidade inerentes à Ponte Flusseriana.
\end{abstract}

\section{Palavras-chave}

Teoria e crítica do design. Filosofia. Arte. Ciência. Técnica.

\section{Flusser, um pensador de causas}

O historiador da arte e do design Rafael Cardoso, interessado na obra flusseriana, organizou e prefaciou o livro $O$ mundo codificado: por uma filosofia do design e da comunicação, de Flusser (2007), cujo subtítulo assinala a relevância e a singularidade dessa obra em teoria e reflexão filosófica, no âmbito do design e da comunicação. No entanto, em tom de advertência, Cardoso (2007) afirma: 
Flusser é um pensador de causas, e não de comportamentos; por conseguinte, ele não hesita em ultrapassar as limitações metodológicas necessárias ao pensamento de cunho histórico. Para áreas marcadas desde sempre pelo predomínio de abordagens e pressupostos advindos das ciências sociais - como é o caso tanto da comunicação quanto do design -, o efeito é surpreendente e enriquecedor. Passado o susto inicial, é melhor dizer, visto que o autor é afeito a generalizações e aproximações capazes de provocar ataques de apoplexia em qualquer cientista social ortodoxo. (CARDOSO, 2007, p. 11).

Se essas características dos textos flusserianos, que aparecem até certo ponto disfarçadas com as provocações de seu autor, perdem na contextualização histórica e sociológica, ganham no aprofundamento nas matrizes estruturantes do pensamento ocidental, ainda preservadas na atualidade, que é o foco de nosso interesse neste artigo. É nesse sentido que entendemos as palavras do filósofo Ernst Cassirer (1992):

[...] toda reflexão histórica genuína, em lugar de se perder na percepção do meramente único, deve buscar aqueles momentos "pejados" do acontecer, para onde confluem, como para pontos focais, séries inteiras de eventos. Em tais pontos, fases temporais, largamente separadas entre si, conectamse em um todo unitário para a concepção e a compreensão histórica. Ao serem certos momentos destacados da corrente uniforme do tempo, estabelecendo relações e concatenando-se em séries, iluminam-se com isso justamente a origem e a meta de todo acontecer, seu de onde (Woher) e seu para onde (Wohin). (CASSIRER, 1992, p. 48, grifo do autor).

Assim, concordando com Cardoso (2007) e com Cassirer (1992), essa transposição de limites tem seu valor genuíno enquanto reflexão filosófica, por voltar-se para as causas $e$ pontos focais na história do pensamento. Para o nosso propósito, abordaremos especificamente dois pequenos escritos de Flusser, reunidos como capítulos no livro $O$ mundo codificado, mas já publicados anteriormente como ensaios separados: Sobre a palavra design e A alavanca contra-ataca. Apesar do peculiar título do segundo texto não explicitar o seu propósito, como veremos, as duas investigações tratam de temas correlacionados.

Sobre a palavra design é um escrito de apenas seis páginas, mas seminal. Como característico das produções de filólogos e filósofos, o texto começa com definições de palavras indo até suas origens, para construir argumentos:

Em inglês, a palavra design funciona como substantivo e também como verbo (circunstância que caracteriza muito bem o espírito da língua 
inglesa). Como substantivo significa, entre outras coisas, 'propósito', 'plano', 'intenção', 'meta', 'esquema maligno', 'conspiração', 'forma', 'estrutura básica', e todos esses e outros significados estão relacionados a 'astúcia' e a 'fraude'. Na situação de verbo - to design - significa, entre outras coisas, 'tramar algo', 'simular', 'projetar', 'esquematizar', 'configurar', 'proceder de modo estratégico'. (FLUSSER, 2007, p. 181, grifo do autor).

Flusser apresenta essas acepções com a clara intenção de reforçar os sentidos do conceito de astúcia, fraude, simulação e trama, que é o centro de seu interesse. Esse propósito é confirmado quando ele também não deixa dúvidas, impondo o mesmo crivo ao definir a atuação do designer:

A palavra design ocorre em um contexto de astúcias e fraudes. 0 designer é, portanto, um conspirador malicioso que se dedica a engendrar armadilhas. Outros termos também bastante significativos aparecem nesse contexto, como, por exemplo, as palavras 'mecânica' e 'máquina'. Em grego, mechos designa um mecanismo que tem por objeto enganar, uma armadilha, e o cavalo de Troia é um exemplo disso. Ulisses é chamado polymechanikos, o que traduzíamos no colégio como 'o astucioso' (der Listenreiche). (FLUSSER, 2007, p. 182, grifo do autor).

A análise e a posição de Flusser são incomuns ${ }^{1}$, se comparadas às de outros teóricos do design que também se detêm sobre os inúmeros sentidos atribuídos nas definições históricas deste campo, como Bernhard Bürdek (2006), Beat Schneider (2010), Gui Bonsiepe (2011), Rafael Cardoso (2008, 2016) e Tomás Maldonado (2012), para citarmos apenas alguns. Flusser transita do conceito de design para o de designer e deste para o de mecânica e de máquina, conectando seus significados com o que ele entende ser sua essência comum: a astúcia. Indo até a origem dessa palavra, ele a associa a Odisseus (ou Ulisses, como ficou conhecido no Ocidente), herói grego e personagem da Odisseia, concebido por Homero para encarnar um caráter único com o epíteto de o astuto.

Neste ponto, importa compreender esse elemento fundamental na dinâmica do texto flusseriano, porque Flusser, para pensar o conceito de astúcia e demais elementos a ele associados, movimenta-se entre um sentido positivo (de sagacidade e habilidade estratégica) e outro negativo (de fraude e conspiração), em uma dialética própria da sua exposição. Para compreendermos essa dinâmica e para seguirmos a trilha aberta por ele

\footnotetext{
1 Entre os anos de 2013 e 2017, lecionamos na Escola de Design da Universidade do Estado de Minas Gerais, para estudantes dos cursos de Design e de Artes Visuais, em turmas do $1^{\circ}$, $2^{\circ}$, $4^{\circ}$, $5^{\circ}$ e e $7^{\circ}$ períodos. Nas diversas oportunidades em que esse ensaio de Flusser foi investigado e discutido em sala de aula, para nossa surpresa (e apesar de não procedermos com nenhuma pesquisa empírica), um número expressivo de estudantes concordou com Flusser na associação do conceito de astúcia ao design e aos designers.
} 
mesmo no âmbito da mitologia grega, é preciso nos determos, mesmo que de forma não aprofundada, sobre narrativas de origem e de conquista do conhecimento em nossa cultura. Trabalharemos tanto com a narrativa grega quanto com o texto bíblico da tradição judaicocristã, uma vez que, no nosso entendimento, as diferenciações desses escritos trazem elementos correlatos em uma dialética que Flusser (judeu e europeu) explora no tratamento de seu tema. Investigaremos especificamente os atributos que tornaram o ser humano distinto dos outros seres e o destacaram da natureza. 0 tema cresce em complexidade e importância na medida em que as duas narrativas a serem analisadas contêm elementos em oposição, como nas contraposições do ensaio de Flusser, o que norteará nossa investigação.

\section{Engenho grego e ardil bíblico: uma dialética para o ato criativo}

Entre as diversas cosmogonias que de algum modo influenciaram e continuam a ter relevância nas concepções de realidade no Ocidente, a de origem grega é uma das que se destaca, por sua capacidade de conectar os discursos primordiais míticos com o subsequente pensamento racional da filosofia. A concepção grega de força produtora (póiesis), fonte da vida, se insere nessa categoria, em que um deus ou demiurgo produz o kósmos a partir do khaos, uma massa preexistente e informe. De modo distinto dessa construção, encontra-se a narrativa bíblica, em que Deus produz, ou mais exatamente cria o mundo a partir do nada (ex nihilo). Tal diferenciação entre concepções é essencial, pois ela se traduz em duas espécies de caminhos para o ato criativo.

Grosso modo, na concepção grega existem modelos a descobrir para efetivar a produção, o que carreia a racionalização para o interior do processo criativo. Na concepção judaico-cristã, se não é possível explicar racionalmente tal processo, elementos como a imaginação, a originalidade e a subjetividade conduzem à ideia de inspiração divina e de gênio criativo como o liame entre os correlatos criador e criatura, e artista e criação. Ao longo da história da cultura ocidental, essas duas visões se alternaram e disputam ainda hoje a primazia da explicação dos processos criativos².

Seguindo adiante nas duas cosmogêneses, de um lado elegemos o mito de Prometeu, cujo personagem principal, um semideus astuto e capaz de antever o futuro, dá

\footnotetext{
2 Para uma análise comparativa dessas duas concepções, com suas características e seus pontos fortes e fracos, ver o artigo $A$ Teoria de Solução de Problemas Inventivos (TRIZ) como complementar aos processos intuitivos de criatividade no design (SILVA; DOMINGUES; DIAS, 2018). Nessa investigação, defendemos a ideia de que, se não for possível unificar as duas visões (a intuitiva e a racional) em um mesmo procedimento, pelo menos é aceitável trabalhar com ambas como instrumentos complementares, e não excludentes, de suporte à criação, potencializando-os mutuamente.
} 
título à narrativa. Com o objetivo de salvar a raça humana da extinção, Prometeu furta o conhecimento técnico da deusa Athená e o fogo e a arte de plasmar metais do deus Hefestos. Com isso ele garante aos homens condições de sobreviver diante dos elementos da natureza, em pé de igualdade com os outros seres vivos. 0 ser humano, que não tinha acesso a esses conhecimentos, tendo-os recebido como presentes, garante sua sobrevivência. Mas, uma vez de posse desse saber, a humanidade não cessa de ampliá-lo, elevando-se em relação aos demais seres, buscando controlar a natureza em benefício próprio e consequentemente aproximando seus atributos aos da divindade.

No livro bíblico do Gênesis, há uma narrativa correlata ao Prometeu, que fala de uma árvore do conhecimento do bem e do mal, e seu fruto acessível, apesar de ser expressamente proibido para a mulher e o homem, sob pena de morrerem. A Serpente, o mais astuto dos animais, atua de modo a enganar a mulher e convencê-la a comer e a dar de comer ao homem. Adão e Eva, antes de comerem do fruto, vivendo no Éden, não correm o risco de perecerem. Mas o castigo dado a eles pela transgressão se estende também a toda a sua descendência, com a perda do paraíso e da vida eterna e a aquisição de uma capacidade de conhecer não apenas o bem, mas também o mal.

Nosso objetivo em relação às duas narrativas, apesar das semelhanças entre elas, é ressaltar suas diferenças ${ }^{3}$, para confrontá-las com o pensamento de Flusser, buscando compreender os vínculos que ele propõe para o design em sua relação com a arte, a ciência, a técnica e a natureza. No Prometeu, a humanidade não vivia em um paraíso, mas sim corria o risco de extinção por não ter as proteções e capacidades naturais dos demais seres vivos. Além disso, a punição que os humanos sofreram após o furto de Prometeu, de serem obrigados a trabalhar para sobreviver, é apenas uma parte do que padece o homem bíblico com a expulsão do paraíso. 0 titã Prometeu, apesar de ser condenado a ficar preso a uma rocha e a ter o fígado dilacerado todos os dias por uma ave de rapina, permanece na sua condição de imortal.

Assim, tanto Prometeu quanto a Serpente são astutos, catalisam o processo da aquisição do conhecimento e fazem uso de um ardil. No entanto, Prometeu é retratado como herói, enaltecido como benfeitor da raça humana, e não perde seu status de semideus, ao passo que a Serpente é descrita como o ser maldito que engana e desencadeia os males

\footnotetext{
3 Na história de Prometeu existiam variantes orais, que foram cristalizadas em inúmeras versões de poetas e tragediógrafos, ao contrário do texto unificado da Bíblia. Assim, destacam-se, entre outros autores, Hesíodo, Ésquilo e até Platão, que narram com diferenças a saga de Prometeu. Conforme afirma o classicista Junito de Souza Brandão (1986), “O mito, como já se assinalou, vive em variantes; ora, a obra de arte, de conteúdo mitológico, somente pode apresentar, e é natural, uma de suas variantes. Acontece que, dado o imenso prestígio da poesia na Grécia, a variante apresentada por um grande poeta impunhase à consciência pública, tornando-se um mito canônico, com esquecimento das demais variantes, talvez artisticamente menos eficazes, mas nem por isso, menos importantes do ponto de vista religioso." (BRANDÃ0, 1986, p. 27).
} 
sobre a humanidade, sendo punida com uma vida rastejante, alimentando-se de pó. Além disso, o conhecimento adquirido pelos protegidos de Prometeu é algo valioso, que encerra uma visão virtuosa e nobre da faculdade de conhecer, enquanto o conhecimento advindo do fruto bíblico está cindido em um maniqueísmo que o torna um risco constante para a humanidade.

Desse modo, um espírito positivo, e, em certo sentido, até otimista em relação ao conhecimento e ao ato de conhecer, perpassa narrativas da cultura grega e reaparece em outras histórias que a formam e estruturam, como a Ilíada e a Odisseia de Homero, de que Flusser se apropria com o propósito de elaborar seu raciocínio. Como é sabido, o personagem Ulisses, no livro da Ilíada, usando de seu atributo principal, a astúcia, escondese com seus guerreiros em um grande cavalo de madeira, que é a chave para a vitória contra a cidade de Ílion (Troia). No livro seguinte, Odisseia, esse herói consegue enfrentar com engenhosidade toda a sorte de dificuldades e aventuras e retornar a salvo à sua terra e ao seu lar.

A disposição grega para entender a astúcia em sua acepção de valor a se preservar ressurge em outras narrativas, como por exemplo, na lenda do Nó Górdio. Essa história narra a solução inusitada que Alexandre, o Grande, teria dado para desfazer um nó em cordas que era aparentemente impossível desatar. Após um tempo estudando a amarração, Alexandre desembainha sua espada e corta o nó. Essa atitude, entendida pela tradição grega positivamente, como sagacidade, engenhosidade e argúcia, também pode ser interpretada negativamente, como fraude, ardil ou trapaça. Como Flusser transita entre duas acepções e medidas valorativas, consideramos essa dupla visão (grega e judaico-cristã) uma chave de leitura para compreender a sua concepção acerca dos pressupostos que animam o design.

Após definir "design" e "designer", Flusser, na mesma trilha etimológica, procura caracterizar tanto a técnica quanto a arte, indo até as suas raízes gregas, que são comuns. Sigamos seus passos:

Outra palavra usada nesse mesmo contexto é 'técnica'. Em grego, techné significa 'arte' e está relacionada com tekton ('carpinteiro'). A ideia fundamental é a de que a madeira (em grego, hylé) é um material amorfo que recebe do artista, o técnico, uma forma, ou melhor, em que o artista provoca o aparecimento da forma. (FLUSSER, 2007, p. 182, grifo do autor).

Essa descrição está claramente vinculada ao conceito de produção demiúrgica, em que preexiste um material amorfo (equivalente ao khaos), que deve ser trabalhado e 
enformado pelo artista. Em seguida, ele avança para a língua latina, com o mesmo procedimento etimológico e viés em torno do artifício, enquanto fraude:

O equivalente latino do termo grego techné é ars, que significa, na verdade, 'manobra' (Dreh). 0 diminutivo de ars é articulum - pequena arte -, e indica algo que gira ao redor de algo (como por exemplo a articulação da mão). Ars quer dizer, portanto, algo como 'articulabilidade' ou 'agilidade', e artifex ('artista') quer dizer 'impostor'. 0 verdadeiro artista é um prestidigitador, o que se pode perceber por meio das palavras 'artifício', 'artificial' e até mesmo 'artilharia'. (FLUSSER, 2007, p. 183, grifo do autor).

Aqui, Flusser vai além das definições clássicas gregas de artista e se alinha especificamente com o conceito platônico de artista, pois poderíamos afirmar que um impostor ou prestidigitador é na essência um imitador (mimetés), como defende Platão (1987) em seu diálogo A república. É importante destacar que esses termos se ligam na origem com outros com os quais atualmente não fazemos normalmente conexão. Por exemplo, o mesmo sentido de impostor encontra-se também em um dos significados de hipócrita, que em sua origem grega tem como uma das suas acepções principais a de ator.

\section{Cisão e hierarquização das áreas do conhecimento}

Tendo essas associações estabelecidas, Flusser pode então retomar a questão do design na atualidade, indicando um problema que, segundo ele, se instaura no período moderno e defender sua tese acerca do papel do design neste contexto:

Essas considerações explicam de certo modo por que a palavra design pôde ocupar o espaço que lhe é conferido no discurso contemporâneo. As palavras design, máquina, técnica, ars e Kunst [ $\left.{ }^{4}\right]$ estão fortemente interrelacionadas; cada um dos conceitos é impensável sem os demais, e todos eles derivam de uma mesma perspectiva existencial diante do mundo. No entanto, essa conexão interna foi negada durante séculos (pelo menos desde a Renascença). A cultura moderna, burguesa, fez uma separação brusca entre o mundo das artes e o mundo da técnica e das máquinas, de modo que a cultura se dividiu em dois ramos estranhos entre si: por um lado, o ramo científico, quantificável, 'duro', e por outro o ramo estético, qualificador, 'brando'. Essa separação desastrosa começou a se tornar insustentável no final do século XIX. (FLUSSER, 2007, p. 183, grifo do autor).

${ }^{4}$ Nesse ensaio, Flusser, tcheco nascido em Praga, também apresenta o correlato de cada palavra definida em alemão. Já que não incluímos essa língua no escopo de nossa análise, não nos estendemos sobre essas comparações. 
Essa citação merece especial atenção. Flusser defende uma inter-relação entre os conceitos de design e máquina, técnica e arte, com a qual concordamos, pelo menos em parte. Nossa posição difere da desse autor quanto ao momento em que ocorreu a cisão entre esses conceitos. Para Flusser (2007), tal separação entre ciência, técnica e arte ocorre "pelo menos" a partir da Renascença, enquanto para nós ela se inicia por volta de 400 a. C. com Platão, com sua teoria acerca da realidade que cinde o conhecimento em áreas (Figura 1 e Figura 2). Mas o mais importante: para nós, tal teoria também hierarquiza de modo problemático o conhecimento, estabelecendo a ciência como a produção que está no topo do saber (SILVA, 2019).

Figura 1 - Linha do tempo do desdobramento do conceito grego de póiesis (produção) em epistéme (ciência) e tékhne (arte) e sua divisão em ciência, técnica e arte em seus sentidos modernos

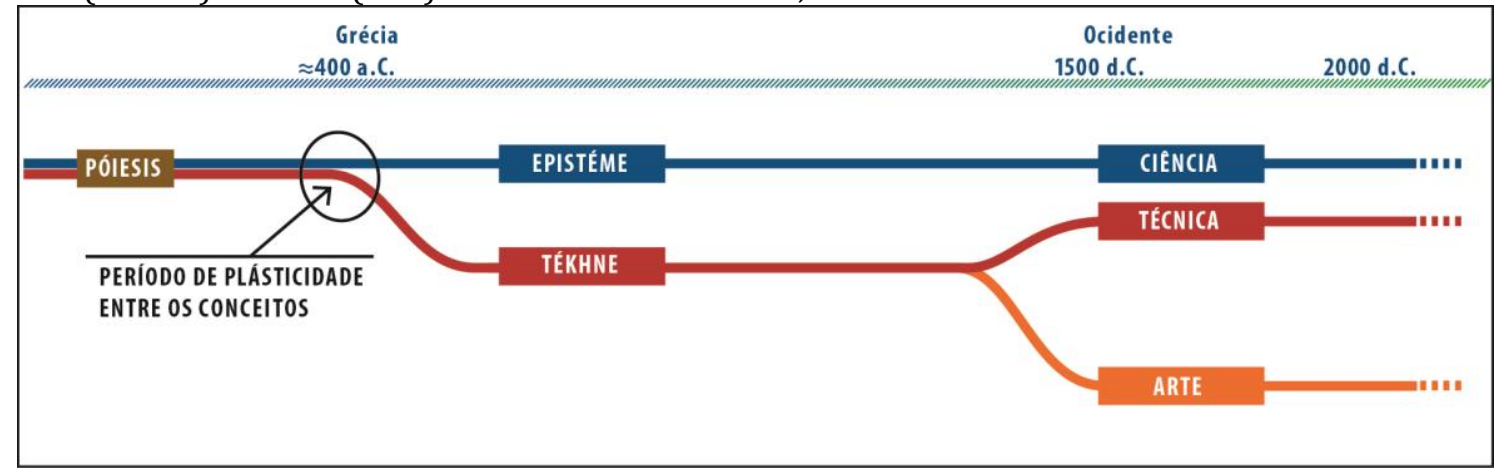

Fonte: Silva (2019).

Figura 2 - Representação das três categorias de produção e a relação das produções humanas (tékhne e epistéme) com seus fundamentos teóricos e com a natureza (phýsis)

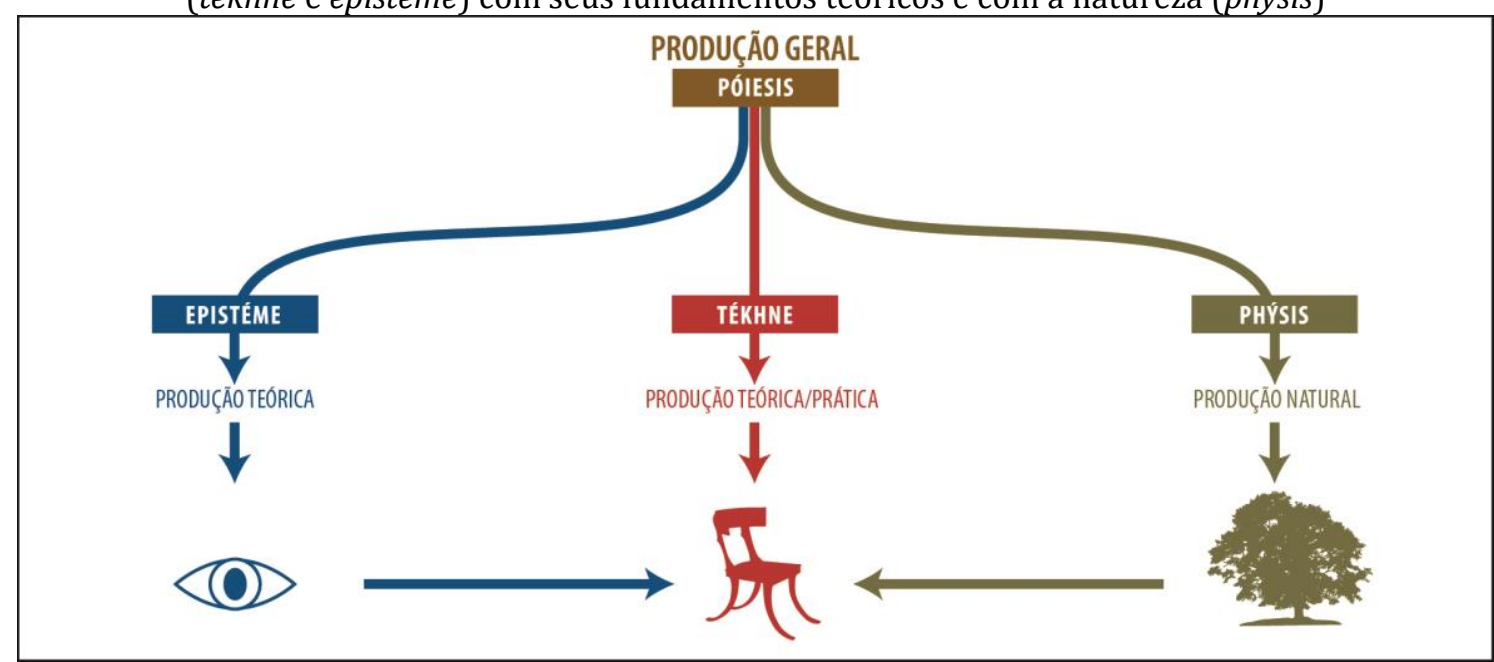

Fonte: Silva (2019).

Independentemente dessas diferenças, a proposta de Flusser (2007) para atenuar essa "separação desastrosa" ou "brecha", entendida com "insustentável", é relevante: 
A palavra design entrou nessa brecha como uma espécie de ponte entre esses dois mundos. E isso foi possível porque essa palavra exprime a conexão interna entre técnica e arte. E por isso design significa aproximadamente aquele lugar em que arte e técnica (e, consequentemente, pensamentos, valorativo e científico) caminham juntas, com pesos equivalentes, tornando possível uma nova forma de cultura. (FLUSSER, 2007, p. 183-184, grifo nosso).

Devemos nos manter atentos ao alerta anterior de Rafael Cardoso (2007) sobre a forma de Flusser conduzir seus raciocínios e expressar suas ideias. Por exemplo, nas duas últimas citações ele não se preocupa em explicitar a diferença entre ciência e técnica, permutando o uso desses conceitos. Essa também é uma postura adotada por Platão (1987), em alguns momentos de seus diálogos, como em $A$ república, em relação à tékhne e à epistéme.

Ao mesmo tempo, Flusser não assume, com todas as letras, a existência na atualidade de uma hierarquização do conhecimento. Mas, acreditamos, tal consciência se manifesta em poucas palavras, quando ele qualifica o design para estabelecer a arte e a técnica "com pesos equivalentes". Essa visão peculiar difere sutilmente, por exemplo, do pensamento de Rafael Cardoso (2016), que não considera necessária a ação do design para instituir a equidade entre a arte e outros campos: "Arte é um meio de acesso ao desconhecido, em pé de igualdade com a ciência, a filosofia, a religião [...]" (CARDOSO, 2016, p. 246).

Outro ponto a destacar: quando Flusser emprega o termo conexão interna, pode parecer que ele compreende design e arte como indistintos. No entanto, as palavras caminham juntas, indicam que seguem uma mesma direção, mas não de indistinção entre áreas. Isso se torna mais claro com o seu conceito de ponte, pois a indistinção não carece desse artifício de ligação. Assim, paradoxalmente, o ponto de vista de Flusser, um filósofo que procura conectar design e arte, não necessariamente se opõe à posição, por exemplo, de Gui Bonsiepe (2011), um designer que pensa a filosofia para distinguir design e arte: "Há muito tempo dispomos de conceitos filosóficos para fazer distinção entre arte e design. Classificar design em categorias artísticas só pode ser explicado por critérios da política de distribuição de verbas nas universidades." (BONSIEPE, 2011, p. 181). Além disso, podemos afirmar que ambos concordam com outra conexão: aquela entre design e ciência/técnica. Novamente conforme Bonsiepe (2011): "Estou convencido de que, no futuro, haverá uma interação frutífera entre mundo das ciências e o mundo do projeto que, hoje, se dá, no máximo, esporadicamente." (BONSIEPE, 2011, p. 17). 


\section{Consequências da astúcia e da fraude}

Até aqui, portanto, comprovamos posições congruentes entre Flusser (2007), Cardoso (2008) e Bonsiepe (2011). Mas a questão da astúcia e da fraude ainda precisa ser esclarecida para compreendermos o alcance da concepção flusseriana:

A cultura para a qual o design poderá melhor preparar o caminho será aquela consciente de sua astúcia. A pergunta é: a quem e ao que enganamos quando nos inscrevemos na cultura (na técnica e na arte, em suma, no design)? Vamos a um exemplo: a alavanca é uma máquina simples. Seu design imita o braço humano, trata-se de um braço artificial. Sua técnica provavelmente é tão antiga quanto a espécie Homo sapiens, talvez até mais. E o objetivo dessa máquina, desse design, dessa arte, dessa técnica, é enganar a gravidade, trapacear as leis da natureza e, ardilosamente, liberar-nos de nossas condições naturais por meio da exploração estratégica de uma lei natural. Por intermédio de uma alavanca - e apesar de nosso próprio peso - podemos nos lançar até as estrelas, se for o caso; e, se nos derem um ponto de apoio, somos capazes de tirar o mundo de sua órbita. Esse é o design que está na base de toda cultura: enganar a natureza por meio da técnica, substituir o natural pelo artificial e construir máquinas de onde surja um deus que somos nós mesmos. Em suma: o design que está por trás de toda cultura consiste em, com astúcia, nos transformar de simples mamíferos condicionados pela natureza em artistas livres. (FLUSSER, 2007, p. 184).

Flusser entende, assim, o caráter da astúcia como inerente à nossa cultura. 0 exemplo da alavanca, que será retomado no segundo ensaio deste pensador, já aparece aqui, de modo a explorar o aspecto positivo, e diríamos culturalmente grego, da astúcia, ou seja, sua capacidade de libertar os seres humanos através da condição de artistas, que lhes permitirá alcançar as estrelas e que poderá até torná-los deuses. Mas a dialética de

Flusser não para neste ponto. Ele entende que

[...] um ser humano é um design contra a natureza [...] [e que] se o design continuar se tornando cada vez mais o foco de interesse, e as questões referentes a ele passarem a ocupar o lugar das preocupações concernentes à ideia certamente não pisaremos em chão firme. (FLUSSER, 2007, p. 185).

Nesse movimento dialógico, em um jogo de oposições, Flusser (2007) aponta o que pagamos por assumirmos a astúcia como intrínseca à nossa cultura:

Como explicar essa desvalorização de todos os valores? Pelo fato de que, graças à palavra design, começamos a nos tornar conscientes de que toda cultura é uma trapaça, de que somos trapaceiros trapaceados, e de que 
todo envolvimento com a cultura é uma espécie de autoengano. [...] Mas o preço que pagamos por isso é a renúncia à verdade e à autenticidade. 0 que a alavanca faz, de fato, é tirar de órbita tudo o que é verdadeiro e autêntico e substituí-lo mecanicamente por artefatos desenhados com perfeição. Desse modo, todos os artefatos adquirem o mesmo valor que as canetas de plástico: convertem-se em gadgets descartáveis. E isso se evidencia, no mais tardar, quando morremos. Pois, apesar de todas as estratégias técnicas e artísticas (apesar da arquitetura do hospital e do design do leito de morte), o fato é que morremos, como todos os mamíferos. A palavra design adquiriu a posição central que tem hoje no discurso cotidiano porque estamos começando (e provavelmente com razão) a perder a fé na arte e na técnica como fontes de valores. Porque estamos começando a entrever o design que há por trás delas. (FLUSSER, 2007, p. 185-186, grifo do autor).

Nesse ponto, claramente, o tom e a argumentação flusseriana procuram identificar os aspectos negativos de assumirmos o que ele entende como um modo de vida artificial, sem verdade e autenticidade. Flusser acredita que junto com a identificação e aceitação da astúcia e com a busca pela perfeição, renunciamos a diversos valores na arte e na técnica. Apesar de entendermos esse estilo, que oscila entre polos, como essencial à sua narrativa, não concordamos com Flusser em que a perda ou rejeição desses valores possa ser creditada à astúcia inerente ao homem e aos princípios que constituem a essência do design. A ambivalência que esse autor explora nesse conceito (que associamos à cultura ocidental, ora em direção a uma compreensão da vida como um presente de Prometeu, ora como a perda da imortalidade e da existência aprazível pela cilada da Serpente bíblica) não indica a real causa das possibilidades que o design enquanto ponte pode nos oferecer.

No nosso entendimento, o perigo no uso que fazemos da astúcia não diz respeito propriamente ao fato de sermos astutos, mas à nossa capacidade de discernir valores e às direções a que nossas escolhas conscientes podem nos levar. Flusser talvez esteja ciente disso, quando afirma, ao final do seu texto, que: "Este ensaio segue um design determinado: ele quer trazer à luz os aspectos pérfidos e ardilosos da palavra design, que normalmente costumam ser ocultados." (FLUSSER, 2007, p. 186). O autor também aponta que outros caminhos poderiam ser seguidos, mas conclui: "[...] é exatamente assim: tudo depende do design." (FLUSSER, 2007, p. 186). Não consideramos essa afirmação como retórica. 0 conceito de ponte que Flusser propõe é potente o suficiente para fazer pensar sobre as possibilidades que o design tem enquanto um campo com fronteiras móveis. A ampliação expressiva dessas fronteiras está representada no gráfico a seguir (Figura 3), onde linhas partem do design em direção à arte, à técnica, à tecnologia e à ciência. 0 próximo passo é, de 
modo análogo, percorrer o segundo ensaio desse autor, $A$ alavanca contra-ataca, atentando para uma conexão inesperada entre o design e a natureza.

Figura 3 - Linha do tempo acrescentando o design com as influências que esse campo acolheu e as conexões que Flusser propõe como desdobramento de suas atividades

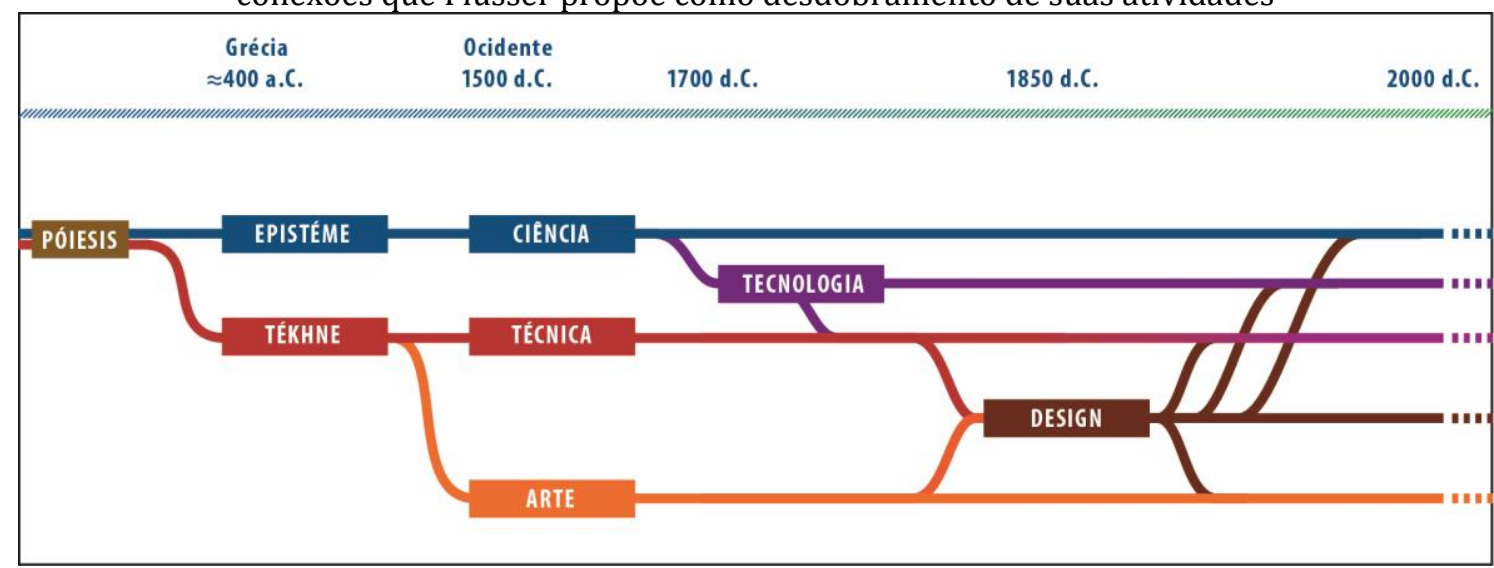

Fonte: Silva (2019).

\section{Uma inusitada ponte em direção à natureza}

Existe um liame visível entre o primeiro e segundo ensaio de Flusser a que se aludiu. Da mesma forma que Flusser coloca a astúcia no centro da discussão no primeiro ensaio, ele o faz conduzindo esse caráter de artifício para o conceito de alavanca no segundo. Flusser inicia essa reflexão, de quatro páginas, novamente com uma definição: “As máquinas são simulações dos órgãos do corpo humano." (FLUSSER, 2007, p. 46). Em seguida, ele retoma os primórdios da vida humana, imaginando, na pré-história, alguns instrumentos que contribuíram para o desenvolvimento de nossa espécie. Tanto a alavanca quanto a faca de pedra são enquadradas na categoria de máquinas inorgânicas, enquanto o burro, o chacal (que podemos interpretar como o cão) e o escravo pertencem à classe das máquinas orgânicas. Ao critério de distinção entre máquinas vivas e inanimadas seguem-se as vantagens e desvantagens de cada um desses gêneros. As inorgânicas são mais fortes, mais resistentes e consequentemente duram mais. No entanto, são "estúpidas". Já as orgânicas duram menos, mas por sua complexidade são consideradas "inteligentes"5 (FLUSSER, 2007, p. 46-47). Em seguida, em um salto - na expressão de Cassirer (1992) - para outro "ponto

\footnotetext{
5 O próprio Flusser insere aspas ao se referir à característica "estúpida" ou "inteligente", destacando o sentido figurado desses termos nessa situação.
} 
focal" da história, que ilumina eventos relacionados, Flusser aborda a época da Revolução Industrial, durante a qual uma inflexão e uma mudança sensíveis ocorrem:

A máquina industrial se distingue da pré-industrial pelo fato de que aquela tem como base uma teoria científica. Certamente a alavanca pré-industrial também tem a lei da alavanca em seu bojo, mas somente a industrial sabe que a tem. Habitualmente isso se expressa assim: as máquinas préindustriais foram fabricadas empiricamente, ao passo que as industriais o são tecnicamente. (FLUSSER, 2007, p. 47).

Aqui, a semelhança da posição de Flusser com o pensamento do historiador da ciência Alexandre Koyré (1991) é evidente:

De minha parte, acredito que a história, ou melhor, a pré-história da revolução técnica dos séculos XVII e XVIII confirma a concepção cartesiana

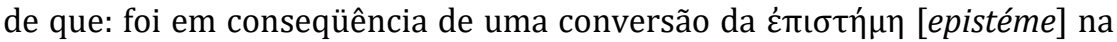

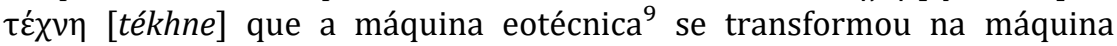
moderna (paleotécnica) ${ }^{6}$; pois, foi essa conversão, em outros termos, foi a tecnologia nascente que atribuiu à segunda aquilo que forma o seu caráter próprio e a distingue radicalmente da primeira, ou seja nada mais do que a precisão. (KOYRÉ, 1991, p. 275, grifo do autor). ${ }^{7}$

Se, para Koyré (1991), as teorias científicas são o fundamento da diferenciação que conduz da técnica à tecnologia, para Flusser (2007 essas mesmas teorias distinguem máquinas pré-industriais e industriais. Até o período histórico em que esse processo de diferenciação ocorre é o mesmo para ambos os autores. Flusser não faz uso dos mesmos termos de Koyré (AAAA1991), mas é clara sua aderência a essa compreensão, que se mostrará uma das bases para ele pensar o design. Não sem razão, na Figura 3, preservamos o elemento da tecnologia e sua linha de derivação, que vai da ciência até o design.

As teorias a respeito do mundo inorgânico, que possibilitaram as máquinas da Revolução Industrial, trazem vantagens em relação às duas classes de máquinas anteriores. Mas e quanto ao homem e sua relação com esses instrumentos? Flusser (2007) prossegue em seu raciocínio mostrando a inversão que ocorre:

Daí que, a partir da Revolução Industrial, o boi deu lugar à locomotiva, e o cavalo, ao avião. 0 boi e o cavalo eram impossíveis de ser feitos tecnicamente. Com relação aos escravos, a coisa era ainda mais complicada. As máquinas técnicas não apenas iam se tornando cada vez

\footnotetext{
${ }^{6}$ A terminologia de Lewis Mumford (1923) inclui, além das máquinas eotécnicas e paleotécnicas, as mais atuais, neotécnicas.

${ }^{7}$ Koyré, na citação, insere uma nota (nota 9), remetendo ao seguinte texto: "Emprego a terminologia extremamente sugestiva do Sr. Lewis Mumford, Technics and Civilisation [sic], 4⿳a ed., New York, 1946." (KOYRE, 1991, p. 288)
} 
mais eficazes como também maiores e mais caras. Desse modo, a relação 'homem-máquina' inverteu-se de tal modo que as máquinas não serviam aos homens, mas estes serviam a elas. Haviam-se convertido em escravos relativamente inteligentes de máquinas relativamente estúpidas. (FLUSSER, 2007, p. 47).

Simultaneamente, ele se pergunta acerca de uma nova fronteira que precisava ser ultrapassada pela ciência: “[...] em relação ao mundo orgânico, as teorias eram bastante escassas. Que leis tem o burro no seu ventre? Não só o próprio burro as desconhecia, como também os cientistas pouco sabiam sobre elas.” (FLUSSER, 2007, p. 47). Esse passo é importante porque marca um giro em direção à natureza, ápice do ensaio flusseriano. Assim, ele vai da revolução dos séculos XVIII e XIX, de caráter predominantemente inorgânico, para a do século XX, que volta parte das suas atenções para o mundo orgânico. Nas suas palavras:

Mas essa não é a mudança realmente importante. Muito mais significativo é o fato de que estamos começando a dispor também de teorias que se aplicam ao mundo orgânico. Começamos a saber que leis o burro traz no ventre. Em consequência, em breve poderemos fabricar tecnologicamente bois, cavalos, escravos e superescravos. Isso será chamado, provavelmente, a segunda Revolução Industrial ou a Revolução Industrial 'biológica'. (FLUSSER, 2007, p. 48).

Flusser chama a nossa atenção para um ramo da ciência que avança sobre um novo território: a vertente biológica da natureza (phýsis), com os seus atributos de autonomia e autoprodução, desde os gregos sem possibilidade de intervenção e dominação humana (conferir Figura 2). Essa visão de mundo cede lugar à extraordinária ampliação do conhecimento que vem ocorrendo desde meados do século XX (a partir da elaboração de teorias como a do DNA). Com isso, tornou-se inevitável o gradativo controle da ciência (epistéme) sobre a produção natural (phýsis) em um nível de compreensão não imaginado pelos gregos nem pela tradição que se seguiu até aquele momento. Assim, após mostrar que estamos unindo as vantagens do mundo inorgânico com as do orgânico, Flusser afirma o resultado dessa hibridização. Metaforizada pelo autor nas figuras dos "chacais de pedra", tal ingerência da produção teórica na produção natural pode tornar as máquinas resultantes mais "espertas" e levá-las a nos contra-atacar, como uma alavanca que devolve o golpe, causando dor (FLUSSER, 2007, p. 48-49):

A velha alavanca nos devolveu o golpe: movemos os braços como se fossem alavancas, e isso desde que passamos a dispor delas. Imitamos os nossos imitadores. Desde que criamos ovelhas nos comportamos como 
rebanhos e necessitamos de pastores. Atualmente, esse contra-ataque das máquinas está se tornando mais evidente: os jovens dançam como robôs, os políticos tomam decisões de acordo com cenários computadorizados, os cientistas pensam digitalmente e os artistas desenham com máquinas de plotagem. Por conseguinte, toda futura fabricação de máquinas também deverá levar em conta o contragolpe da alavanca. Já não é possível construir máquinas considerando apenas a economia e a ecologia. É preciso pensar também como essas máquinas nos devolverão seus golpes. Uma tarefa difícil, se levarmos em consideração que, na atualidade, a maioria das máquinas é construída por 'máquinas inteligentes' e nós apenas observamos o processo para intervir ocasionalmente. (FLUSSER, 2007, p. 49).

Essa visão impressiona em seu aspecto preditivo, uma vez que este ensaio de Flusser foi escrito ainda no século $\mathrm{XX}^{8}$. No entanto, sua proposta mais radical, com a qual ele encerra o ensaio, não diz respeito a essas antecipações e exercícios de futurologia, mas tem a ver com sua decisão de colocar o design no centro da “Revolução Industrial 'biológica'” e se perguntar sobre a capacidade do designer de elaborar soluções para os efeitos do contragolpe da alavanca (FLUSSER, 2007):

Esse é um problema de design: como devem ser as máquinas, para que seu contragolpe não nos cause dor? Ou melhor: como devem ser essas máquinas para que o contragolpe nos faça bem? Como deverão ser os chacais de pedra para que não nos esfarrapem e para que nós mesmos não nos comportemos como chacais? Naturalmente podemos projetá-los de modo a que nos lambam, em vez de morder-nos. Mas queremos realmente ser lambidos? São questões difíceis, porque ninguém sabe de fato como quer ser. No entanto, devemos debater essas questões antes de começarmos a projetar chacais de pedra (ou talvez clones de invertebrados ou quimeras de bactérias). E essas questões são ainda mais interessantes do que qualquer chacal de pedra ou qualquer futuro superhumano. Será que o designer estará preparado para colocá-las? (FLUSSER, 2007, p. 49-50).

É notável que Flusser, um filósofo, transfira, pelo menos em parte, a responsabilidade de reflexão sobre os fins do homem e da natureza, da esfera da filosofia e da ciência, para o âmbito do design, incluindo o designer no debate dessas questões, que devem, segundo ele e com razão, preceder aos projetos. A Figura 4 (em relação à Figura 3)

\footnotetext{
8 Não encontramos referência à data da publicação original deste ensaio, mas Flusser morre em 1991, o que distancia suas reflexões dos rápidos avanços científicos e tecnológicos do século atual e reforça o tom profético de sua narrativa. Sua preocupação é compartilhada por outros teóricos e escritores desse período. 0 teor de suas palavras lembra também a efervescência dos temas de ficção científica de clássicos da literatura, como os livros Admirável mundo novo, publicado em 1932 ,de Aldous Huxley; Eu, robô, publicado em 1950, de Isaac Asimov; Androides sonham com ovelhas elétricas?, publicado em 1968, de Philip K. Dick, levado ao cinema em 1982 por Ridley Scott em Blade Runner: o caçador de androides e o conto Sentinela, publicado em 1951, de Arthur C. Clarke, que foi a base para o filme 2001: uma odisseia no espaço, lançado em 1968, de Stanley Kubrick. Os escritos de Flusser parecem estar em constante diálogo com esses autores e obras.
} 
apresenta duas novas conexões: uma entre ciência e natureza e outra, que surpreendentemente representa a concepção de Flusser, entre design e natureza.

Figura 4 - Linha do tempo incluindo a ligação entre ciência e natureza e a proposta de Flusser para a ligação entre design e natureza

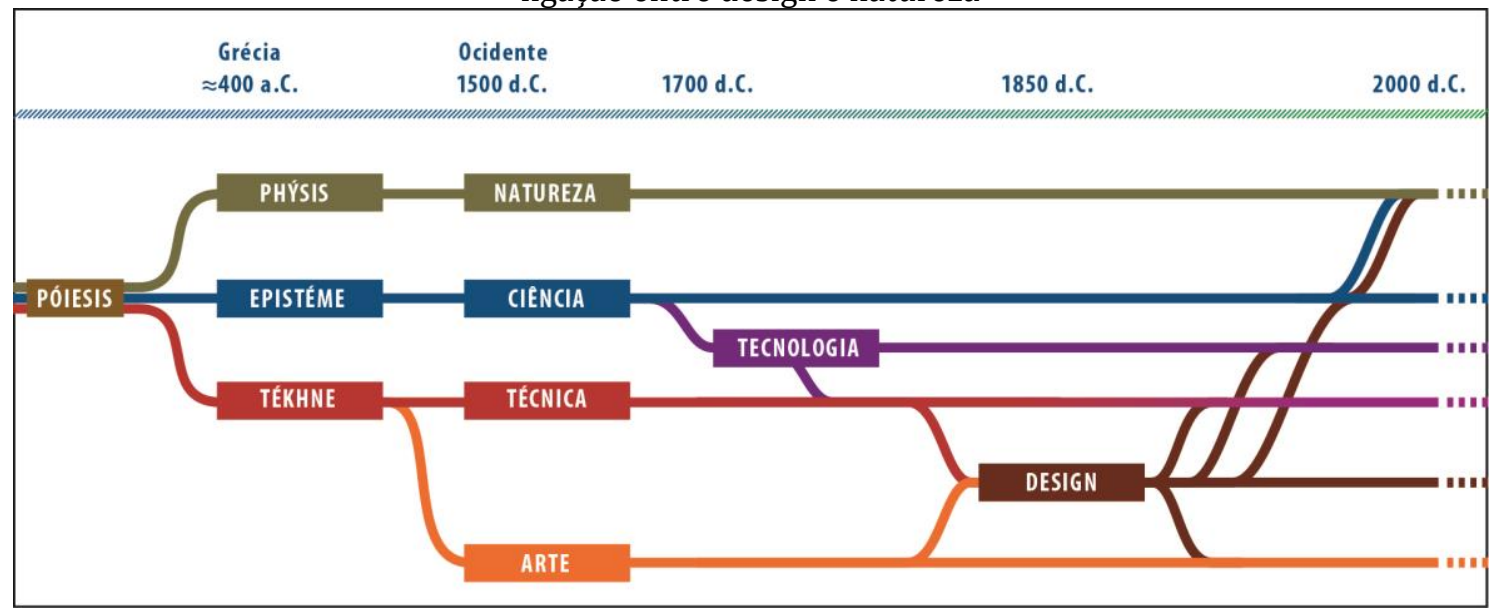

Fonte: Silva (2019).

Talvez o deslocamento ou rearranjo de compromissos esteja associado ao conceito de projeto com o qual Flusser abarca também o mundo biológico em suas quimeras de bactérias Nesse sentido, confirmamos que Bonsiepe (2011) tem uma compreensão alinhada com a proposta flusseriana:

\begin{abstract}
Não se pode mais restringir o conceito de projeto às disciplinas projetuais como ocorre na arquitetura, no design industrial e no design de comunicação visual, pois nas disciplinas científicas também há projeto. Quando um grupo de engenheiros agrônomos desenvolveu uma nova merenda, com base na semente de algaroba acrescida de sais minerais e vitaminas básicas para escolares, realizou um claro exemplo de projeto. Portanto, já registramos uma zona de contato entre ciências e projeto, embora ainda não tenhamos, até o momento, uma teoria projetual que abarque todas as manifestações projetuais, como na engenharia genética que, sem dúvida alguma, deve ser considerada uma disciplina projetual científica. (BONSIEPE, 2011, p. 19).
\end{abstract}

Na citação anterior, nossa atenção se concentra na semelhança entre a ideia de zona de contato em Bonsiepe e a de ponte em Flusser. As possibilidades que esses dois conceitos liberam para o design e outros campos atuarem como conectores entre áreas do conhecimento são substanciais e promissoras. Bonsiepe (2011) expõe sua ideia sobre uma "teoria projetual" como um vínculo entre diversas áreas. Atuando como epistemólogo, propõe, de modo perspicaz, uma disciplina que, da forma como entendemos, ofereceria 
(enquanto um substrato metafísico) um suporte à etapa de projeto do qual os campos implicados em práticas projetivas poderiam usufruir. De modo similar à visão de Bonsiepe (2011), a ideia de Flusser(2007), no entanto, nos atrai mais pelos diversos desdobramentos que pudemos identificar e que têm proximidade com a compreensão do design enquanto um campo que conecta outros:

a) apesar da semelhança conceitual, diferentemente da "zona de contato", na ideia de "ponte", o design é a própria ponte;

b) o que denominamos Ponte Flusseriana liga ciência de um lado e arte do outro, o que é um modo de nos esquivarmos da problemática cisão entre áreas do saber;

c) a ponte também permite reconsiderar se o problema da hierarquização do conhecimento, advinda da cisão em áreas, pode ser eventualmente mitigado ou até eliminado.

\section{Considerações finais}

Não acreditamos que seja possível retornar a uma compreensão da realidade como um kósmos harmônico em que cada ramo do saber esteja intimamente relacionado aos demais, como na antiguidade grega, pré-platônica. Mas é importante ter esse referencial idílico em mente para pensarmos duas espécies de dificuldades com as quais precisamos lidar na contemporaneidade. Uma, inerente à fragmentação que enfrentamos no âmbito geral da cultura e do saber, que se estabelece de forma acentuada desde o advento da modernidade. Outra, consequência da hierarquização do conhecimento, que afeta diversas áreas, incluindo duas de nosso interesse: design e arte.

Tomás Maldonado é um dos autores que se apresentam, ao lado de Flusser, como mais um dos críticos dessa ruptura, pois une seus argumentos provenientes de conhecimentos no design e na $\operatorname{arte}^{9}$ com um interesse na filosofia da ciência e da técnica, questionando a tradição idealista proveniente de Platão. Ter em conta algumas das críticas de um teórico do design contribui para colocar em perspectiva a proposta flusseriana. Conforme afirma Maldonado (2012):

Vivemos atualmente em um momento particularmente inovador da longa (e atribulada) história da reflexão sobre a técnica. Constata-se, nas últimas

\footnotetext{
Maldonado (2012) formou-se pela Academia de Belas Artes de Buenos Aires em 1939 e participou do movimento de Arte Concreta da Argentina entre os anos de 1943 e 1954, antes de se tornar professor de design e reitor na Alemanha, na escola de Ulm.
} 
décadas, uma tendência cada vez maior de afastamento daquelas interpretações com viés idealista, que sempre dificultaram as tentativas de se fazer reflexão sobre a técnica. [...] Basta pensar, por exemplo, na contribuição de E. Zschimmer (1914) e F. Dessauer (1927 e 1959), dois engenheiros-cientistas-filósofos, de filiação hegeliana e kantiana, respectivamente. Apesar de certos aspectos muito estimulantes de seus pensamentos, esses estudiosos estavam convencidos de que as respostas às questões levantadas pela técnica deveriam ser buscadas dentro da própria técnica. A técnica seria uma realidade autônoma, um sistema fechado, que se desenvolve e se autoexplicaria sem ter de recorrer a fatores exógenos. Poder-se-ia dizer - utilizando um termo agora muito na moda - que a técnica é autopoiética. Dessauer deixa subentendido platônica e aristotelicamente - que as formas dos objetos técnicos já estariam presentes em um catálogo ideal das formas preexistentes. E que a técnica não faria outra coisa a não ser deixá-las explícitas. (MALDONADO, 2012, p. 153).

Três pontos interligados nessa citação devem ser destacados. Primeiro, a crítica de Maldonado (2012) está dirigida às interpretações que se apoiam no idealismo e no platonismo. Segundo, a delimitação da forma mais atual desse idealismo está vinculada ao conceito de autopoiese ou autoprodução. Terceiro (promovendo a conexão dos dois primeiros pontos), este autor faz uma clara remissão dessa concepção de técnica ao ideário platônico, ao relacioná-la com "realidade autônoma" e "catálogo ideal das formas preexistentes" (MALDONADO, 2012). Não há dúvida da crítica direta de Maldonado (2012) à posição platônica, crítica com a qual concordamos. Porém, devemos fazer duas ressalvas sobre pontos em que não estamos de acordo com esse autor.

A primeira é que, na antiguidade, o conceito de póiesis, na sua especificação de existência espontânea, é autoprodução e está intrinsecamente associado à natureza (phýsis), uma potência que gera a si mesma. Mas isso não ocorre na especificação da póiesis nas produções humanas (SILVA, 2019), na forma da epistéme ou tékhne (confira Figura 2). No entanto, seguindo as palavras de Maldonado (2012), que fala de "autopoiética", afirmando ser um termo da moda, podemos supor que talvez ele se refira à "autopoiese", palavra que foi cunhada pelo biólogo e epistemólogo Humberto Maturana (2003), na década de 1970, para caracterizar a capacidade dos seres vivos de produzirem a si próprios e que ficou em evidência com os debates em torno da relevância dos sistemas ${ }^{10}$ na compreensão dos fenômenos biológicos. Apesar de o neologismo autopoiese também remeter à phýsis grega,

\footnotetext{
${ }^{10}$ Sobre a delimitação do conceito de autopoiese, Humberto Maturana e Francisco Varela (2003) afirmam, no livro De máquinas y seres vivos: autopoiesis, la organización de lo vivo: "A compreensão do caráter sistêmico dos fenômenos que envolvem a vivência possibilitada pela teoria da autopoiese permite explicar a origem dos seres vivos na terra, ou em qualquer parte do cosmo, como o surgimento espontâneo de um ser vivo como entidade discreta assim como ocorre a dinâmica molecular autopoiética como um fenômeno sistêmico." (MATURANA; VARELA, 2003, p. 24, tradução nossa).
} 
tanto no conceito quanto na etimologia da palavra poiese, se Maldonado (2012) está apenas se apropriando de sua designação contemporânea relacionada à biologia e aplicando-a em uma concepção de técnica entendida como endógena, a ressalva pode ser mitigada.

A segunda ressalva diz respeito à inclusão que Maldonado (2012) faz do nome de Aristóteles, alinhando-o com o pensamento platônico, pensamento este que também não é idealista11. Aristóteles (1987) se opõe frontalmente a um mundo de formas ideais preexistentes, ou a um "catálogo". Essa é uma das posições fundamentais de Aristóteles, que o coloca historicamente como o primeiro a discordar de Platão, e ela é embasada em argumentos suficientes para justificar nossa escolha de colocar Aristóteles no centro da discussão sobre a crítica a uma hierarquia do conhecimento (SILVA, 2019), numa linha que vai até Flusser e à qual nos filiamos.

No entanto, essa restrição que apontamos não invalida a posição também crítica de Maldonado (2012) em relação a uma concepção de técnica entendida como "um sistema fechado" e consequentemente como uma "realidade autônoma". Neste contexto, é importante também atentar que, mesmo nas concepções de tendência "platônica" que defendem "realidades autônomas", a técnica, compreendida como um campo separado da ciência, se mantém atrelada e hierarquicamente submetida a uma teoria que a fundamenta, e que se efetiva através da tecnologia, como vimos na definição de Koyré 1991). Essa hierarquia, não no caso da técnica, mas especificamente no da tecnologia, talvez não possa ser eliminada, pelo menos em seu modelo atual, diretamente subsidiada pelas teorias da ciência (confira Figura 4).

A questão é complexa e merece uma investigação ampla à parte. Mas, grosso modo, na composição da expressão "realidade autônoma", o fato de Maldonado (2012) empregar o substantivo "realidade" é tão significativo, quanto é expressivo o adjetivo "autônoma", que o acompanha. Como os dois termos têm caráter ontológico, questionar a realidade autônoma da técnica, do modo como Maldonado (2012) procede, implica discordar da ontologia platônica, na qual a realidade se encontra em um mundo ideal e não no mundo físico em que vivemos e atuamos. Porém, há uma sutil diferença e um paradoxo aqui: é preciso entender que essa discordância com a tradição platônica não é o mesmo que uma afirmação

\footnotetext{
${ }^{11}$ De um ponto de vista gnoseológico, o conhecido mundo das ideias de Platão (1987) é concebido como a verdadeira realidade. Para Platão tal mundo é real e os objetos que o compõem, as ideias, possuem propriedades constitutivas reais. Por outro lado, o conceito de idealismo da modernidade (com inúmeras variantes entre seus seguidores), apesar do nome, não tem a ver com o mundo das ideias platônico, mas, grosso modo, com o entendimento de que os objetos não têm existência real fora de nós, sendo construídos em nossa consciência. Para uma leitura introdutória à gnoseologia, o livro Teoria do conhecimento, de Johannes Hessen (1980), expõe de forma simples, mas clara e concisa, as diferenças entre essas e outras posições.
} 
da autonomia da técnica, ou, mais precisamente, da independência da técnica em relação a outros campos com os quais ela se relaciona e tem vínculos, que deveriam ser reforçados, como sugere Flusser (2007), mas sem submetê-la, ou submeter outras categorias do saber a ela.

Além de Maldonado (2012), a disposição de outros pesquisadores do design, como Bonsiepe (2011), Bürdek (2006) e Cardoso (2016), para buscarem conceitos comuns e a identificação de fenômenos em campos distintos, afastando-se de posições platônicas, indicam a aproximação desses teóricos de concepções integradoras, como as de Flusser. Suas investigações, na forma de novas teorias ou princípios organizadores retirados de outros campos, como a filosofia ${ }^{12}$ (alguns defendendo somente as conexões de seus objetos de estudo e outros apostando em um caráter holístico ou totalizante de seus fundamentos), confirmam a relevância das reflexões pouco ortodoxas de Flusser na atualidade.

Assim, unimo-nos a Flusser ao perguntarmos: é possível garantir autonomia, ou independência, a cada uma dessas disciplinas (ciência, técnica, design e arte) e ao mesmo tempo ultrapassar, ou pelo menos mitigar, o modelo de cisão que existe entre elas? A forma paradoxal dessa questão não nos impede de apostarmos que o design pode atuar, não construindo pontes, mas efetivamente sendo uma das pontes que conectam áreas. Com isso, também é possível avançarmos, como sinaliza Flusser, em direção a domínios até então impensados, como o da natureza em seu âmbito biológico.

Com todos os riscos que Flusser aponta, e devemos atentar para eles, o design opera uma ampliação da realidade ou em termos filosóficos, uma operação ontológica, como também procede a arte ${ }^{13} \mathrm{e}$, portanto, tais campos não devem estar subsumidos à ciência e à técnica em uma hierarquia do saber. A partir dessa tomada de posição, outra pergunta precisa ser respondida: com quais elementos tal ponte flusseriana se concretiza? No nosso entendimento, a reelaboração de alguns conceitos aristotélicos, como o de mímesis (SILVA; SILVA, 2013) e o de fim em si mesmo (SILVA; RIBEIRO, 2013), é bemvinda e capaz de estruturar, pelo menos em parte, a realidade dessa ponte entre áreas, pois tais conceitos também são constitutivamente princípios de natureza ontológica.

\footnotetext{
12 Bürdek (2006) é um dos que defende, mesmo que de forma eurocêntrica, a inclusão de fundamentos filosóficos no design: "No desenvolvimento da metodologia e teoria do design, as ciências humanas têm um papel muito especial. A constante crise dos sentidos da disciplina faz sentir uma maior necessidade de reflexão e teoria de filosofia. Por isso, é necessário verificar que aspectos da teoria do design ou da metodologia do design têm fundamento na filosofia europeia." (BÜRDEK, 2006, p. 227). Bürdek (2006) também indica como métodos a fenomenologia de Husserl e a hermenêutica de Schleiermacher, Dilthey e Gadamer, teorias filosóficas essas que, segundo ele, já se encontram minimamente aplicadas em pesquisas de design (BURDEK, 2006).

13 Para uma defesa do estatuto ontológico da arte, principalmente após Marcel Duchamp, ver o livro A transfiguração do lugarcomum de Arthur C. Danto (2005), e para a defesa do estatuto ontológico do design, ver a tese de doutorado Os fundamentos ontológicos das relações entre design e arte (SILVA, 2019).
} 


\section{Referências}

ARISTÓTELES. A poética. Tradução, comentários e índices analítico e onomástico Eudoro de Souza. Coleção Os Pensadores, v. 2. São Paulo: Nova Cultural, 1987.

BONSIEPE, Gui. Design, cultura e sociedade. São Paulo: Blücher, 2011.

BRANDÃO, Junito de Souza. Mitologia grega. Petrópolis: Vozes, ca. 1987. 3 v.

BÜRDEK, Bernhard E. História, teoria e prática do design de produtos. São Paulo:

Blücher, 2006.

CARDOSO, Rafael. Introdução. In: FLUSSER, Vilém. 0 mundo codificado: por uma filosofia do design e da comunicação. São Paulo: Cosac Naify, 2007.

CARDOSO, Rafael. Uma introdução à história do design. 3. ed. São Paulo: Blücher, 2008.

CARDOSO, Rafael. Design para um mundo complexo. São Paulo: Ubu, 2016.

CASSIRER, Ernst. Linguagem e mito. São Paulo: Perspectiva, 1992.

DANTO, Arthur Coleman. A transfiguração do lugar-comum: uma filosofia da arte. São Paulo: Cosac Naify, 2005.

FLUSSER, Vilém. 0 mundo codificado: por uma filosofia do design e da comunicação. São Paulo: Cosac Naify, 2007.

HESSEN, Johannes. Teoria do conhecimento. 7. ed. Coimbra: Arménio Amado, 1980.

KOYRÉ, Alexandre. Estudos de história do pensamento filosófico. Brasília: Forense Universitária, 1991.

MALDONADO, Tomás. Cultura, sociedade e técnica. São Paulo: Blücher, 2012.

MATURANA, Humberto; VARELA, Francisco. De máquinas y seres vivos: autopoiesis, la organización de lo vivo. Buenos Aires: Lumen, 2003.

MUMFORD, Lewis. Technics and civilization. London: Routledge \& Kegan Paul, 1923.

PLATÃO. A república. 5. ed. Lisboa: Fundação Calouste Gulbenkian, 1987.

SCHNEIDER, Beat. Design - uma introdução: o design no contexto social, cultural e econômico. São Paulo: Blücher, 2010.

SILVA, Sérgio Luciano da; RIBEIRO, Rita Aparecida da Conceição. As relações entre arte e design: uma análise de discursos subjacentes e de pressupostos de comunicação. Alceu, Rio de Janeiro, v. 13, n. 26, p. 116-126, 2013.

SILVA, Sérgio Luciano; SILVA, Sérgio Antônio. O Conceito aristotélico de mímesis aplicado ao processo criativo em design. Estudos em Design, Rio de Janeiro, v. 21, n. 1, p. 1-14, 2013. 
SILVA, Sérgio Luciano da; DOMINGUES, Felipe; DIAS, Maria Regina Álvares Correia. A Teoria de Solução de Problemas Inventivos (TRIZ) como complementar aos processos intuitivos de criatividade no design. In: COLÓQUIO INTERNACIONAL DE DESIGN, 4., 2017, Belo

Horizonte. Anais [...]. Belo Horizonte: Blucher Design Proceedings, 2018. p. 44-53.

SILVA, Sérgio Luciano da. Os fundamentos ontológicos das relações entre design e arte. 2019. Tese (Doutorado em Design) - Programa de Pós-Graduação em Design, Universidade do Estado de Minas Gerais, Belo Horizonte, 2019.

Two cosmogonies as keys to understanding Vilém Flusser's bridge of design

\section{Abstract}

This paper seeks to identify and understand the foundations of Vilém Flusser's thought on design, based on the cosmogonic narratives of the Greek Prometheus and the Bible's book of Genesis. Since Flusser's essays Sobre a palavra design and A alavanca contra-ataca discuss the origins of knowledge, we can relate them to these two cosmogonies of Western culture and to our conception of a common root for the various fields of knowledge, which have been split up and sorted into hierarchies. To establish the dialogue with Flusser's philosophy, we referred to Gui Bonsiepe, Rafael Cardoso and Tomás Maldonado. These design theorists follow similar paths to those of the philosopher, calling into question the division of knowledge and the role of design in the face of the split between science, technique and art. As a result of this dialogical and analytical method, we identified and made explicit the capacities for expanding the reality inherent to the Flusserian Bridge.Keywords

Theory and critique of design. Philosophy. Art. Science.

Technique.

Recebido em 26/03/2020

Aceito em 23/07/2020 